\title{
Risk factors associated with the prevalence of tuberculosis-like lesions in fenced wild boar and red deer in south central Spain
}

\author{
Joaquín VICENTEa,b,c*, Ursula HöFLE ${ }^{\mathrm{a}}$, Joseba M. GARRIDO ${ }^{\mathrm{d}}$, \\ Isabel G. FERNÁNDEZ-DE-MERA a , Pelayo ACEVEDO ${ }^{\mathrm{a}}$, Ramón JUSTE ${ }^{\mathrm{d}}$, \\ Marta BARRAL $^{\mathrm{d}}$, Christian GORTAZAR ${ }^{\mathrm{a}}$ \\ a Instituts de Investigación en Recursos cinegéticos - IREC (CSIC-UCLM-JCCM), \\ Ronda de Toledo s/n, 13080 Ciudad Real, Spain \\ ${ }^{\mathrm{b}}$ Ciudad Real Agricultural Engineering School (UCLM), Ronda de Calatrava 7, \\ 13004 Ciudad Real, Spain \\ ${ }^{\mathrm{c}}$ Present address: Wildlife Disease Ecology Team, Central Science Laboratory, Tinkley Lane, \\ Nympsfield, GL103UJ Gloucestershire, United Kingdom \\ ${ }^{\mathrm{d}}$ NEIKER Instituto Vasco de I+D Agraria, C./Berreaga 1, 48300 Derio, Spain
}

(Received 27 January 2006; accepted 19 October 2006)

\begin{abstract}
In recent decades the management of large game mammals has become increasingly intensive in south central Spain (SCS), resulting in complex epidemiological scenarios for disease maintenance, and has probably impeded schemes to eradicate tuberculosis (TB) in domestic livestock. We conducted an analysis of risk factors which investigated associations between the pattern of tuberculosis-like lesions (TBL) in wild boar (Sus scrofa) and red deer (Cervus elaphus) across 19 hunting estates from SCS and an extensive set of variables related to game management, land use and habitat structure. The aggregation of wild boar at artificial watering sites was significantly associated with an increasing risk of detecting TBL in both species, which probably relates to enhanced opportunities for transmission. Aggregation of wild boar at feeding sites was also associated with increased risks of TBL in red deer. Hardwood Quercus spp. forest availability was marginally associated with an increased risk of TB in both species, whereas scrubland cover was associated with a reduced individual risk of TBL in the wild boar. It is concluded that management practices that encourage the aggregation of hosts, and some characteristics of Mediterranean habitats could increase the frequency and probability of both direct and indirect transmission of TB. These findings are of concern for both veterinary and public health authorities, and reveal tuberculosis itself as a potential limiting factor for the development and sustainability of such intensive game management systems in Spanish Mediterranean habitats.
\end{abstract}

Mycobacterium tuberculosis complex / red deer / risk factors / tuberculosis / wild boar

\section{INTRODUCTION}

Tuberculosis (TB) is a low-induced immunity [23] and chronic infectious dis-

\footnotetext{
* Corresponding author: joaquin.vicente@uclm.es
}

ease. Mycobacterium bovis, the causative agent of bovine TB, infects a broad host range $[6,7]$. Bovine $\mathrm{TB}$ in cattle is a major economic problem. In Spain, in previous years, infection in cattle has been reduced by testing-and-slaughter (the overall 
proportion of herds officially considered TB free in the country in 2004 was over $99 \%$ ), but only a moderate decreasing trend has been observed in southern areas, where the proportion of herds officially considered free of TB in 2004 was only 95\% [22]. The re-emergence of $\mathrm{TB}$ and continued failure to eradicate the disease in livestock in many countries have been related to reservoirs of infection in wildlife populations (e.g. $[1,36])$. However, it is simplistic to assume that infection in cattle is due entirely to an inherent reservoir in wildlife [8]. Nevertheless, further understanding of the main factors affecting the persistence of TB in wildlife is likely to be valuable in the development of sustainable approaches to managing the disease in livestock. During recent decades, extensive changes in land-use in Spain have been followed by a marked increase in the abundance and distribution of wild ungulates $[9,30]$, and the development of a commercial recreational hunting industry, especially in south central Spain (SCS). In order to increase hunting harvests, highwire fences have been employed on a large proportion of estates to contain wild ungulates. These populations have essentially become captive, and artificial feeding and watering is usually provided during all or part of the year. TB in wildlife appears to be endemic across a broad geographic region, coincident with the traditional big game hunting areas of SCS [11, 14, 26, 34]. Data suggest that TB in wild boar (Sus scrofa), red deer (Cervus elaphus) and cattle is an endemic and low incidence infectious disease $[11,26]$. Although interspecific transmission rates have never been described, recent work has shown that wild boar and red deer share similar strains from the Mycobacterium tuberculosis Complex [11]. Across this area, tuberculosis-like lesions (TBL) in ungulate populations have been employed as a criterion to evaluate disease distribution using large numbers of animals [34].
This research revealed that TBL in both species were spatially associated, and that the prevalence of TBL was consistently higher in wild boars than in red deer [34]. Within this complex multi-host scenario, the prevalence of TBL in wild boar did not vary according to whether populations were or were not cohabiting with red deer, suggesting involvement of wild boar as a reservoir [34]. This situation is of concern for veterinary and public health authorities (e.g. [7,11,21]) since game ungulates could potentially act as TB reservoirs for domestic livestock. Therefore, understanding the risk factors associated with TB infection in these ungulates is fundamental to the development of effective TB control policies.

Epidemiologic evidence is often the best first step in identifying disease reservoirs and revealing associated risk factors [13]. To date no research has identified management and habitat correlates of TB in wild boar and red deer populations in Spanish Mediterranean habitats. Such information may also provide insights into transmission dynamics at the big game/livestock interface. Our aim was to identify the major management and environmental factors associated with the occurrence of TBL in wild boar and red deer in these areas.

\section{MATERIALS AND METHODS}

\subsection{Study sites}

Data were collected at the individual level, and at the hunting estate level (as a discrete management unit). A variety of hunting estates may be found across SCS, which can be classified as containing captive fenced cervid populations (large enclosures, generally at relatively high densities [12]) or having free-ranging native cervid populations (not enclosed). In addition, a small number of deer farms are present in Spain, although no data were available to include them in the present 
study. Both wild boar and red deer were present on all the study sites.

Study sites were located on the south of the central Spanish plateau. This is a hilly area (altitude of sampling sites ranged from 600 to $1100 \mathrm{~m}$ a.s.l.), which consists of the Montes de Toledo and Sierra Morena mountain chains. The Guadiana river valley, a fragmented Mediterranean habitat, connects them both. The habitat is Mediterranean and characterised by $Q u e r$ cus ilex forests and scrublands (dominated by Cystus spp., Pistacia spp., Rosmarinus spp., Erica spp. and Phyllirea spp.) with scattered pastures and small areas of crops. Annual rainfall is extremely variable (ranging from 300 to $700 \mathrm{~mm}$ ) and the climate is Mediterranean with a continental influence. The wet season typically starts in September-October and contributes most of the annual rainfall. The dry season (from June to September) is when food and water resources become limited for ungulates. Seasonal streams cross many of the estates but in most of them, water is retained in artificial waterholes all year around. These waterholes consist of small ditches across the riverbeds. In these Mediterranean woodland habitats, most of the hunting estates are devoted exclusively to recreational wild boar and red deer hunting, and only a few still maintain traditional livestock. Nevertheless, cattle had been present on most estates until they were fenced for hunting purposes, several decades ago. Other land use, such as arable and extensive sheep and goat farming are more frequent in most non-fenced hunting areas.

\subsection{Sampling and diagnosis}

Data were collected from a crosssectional national survey of TB infection in wild boar and wild Iberian red deer at 19 sites (Tab. I) in SCS, within a $50000 \mathrm{~km}^{2}$ area concentrated on the
Table I. Mean prevalence of macroscopic TB compatible lesions (\%) in the wild boar and red deer at sampling sites included in the risk factor analysis.

\begin{tabular}{lcclcc}
\hline \multirow{2}{*}{$\begin{array}{l}\text { Sampling } \\
\text { site }\end{array}$} & \multicolumn{2}{c}{ Wild boar } & & \multicolumn{2}{c}{ Red deer } \\
\cline { 2 - 3 } \cline { 5 - 5 }$N$ Prevalence $(\%)$ & & $N$ & Prevalence $(\%)$ \\
\hline 1 & 33 & 33.3 & 18 & 22.2 \\
$2^{*}$ & 23 & 30.4 & & 10 & 0.0 \\
$3^{*}$ & 20 & 50.0 & 36 & 5.6 \\
4 & 18 & 88.9 & 25 & 44.0 \\
5 & 20 & 55.0 & 29 & 20.7 \\
6 & 20 & 40.0 & & 14 & 7.1 \\
7 & 13 & 61.5 & 39 & 2.5 \\
8 & 13 & 38.5 & 10 & 0.0 \\
9 & 34 & 58.8 & & 13 & 23.1 \\
10 & 11 & 18.2 & & 24 & 4.2 \\
11 & 15 & 46.7 & 27 & 0.0 \\
12 & 41 & 80.5 & 150 & 18.7 \\
13 & 62 & 51.6 & 38 & 13.2 \\
14 & 14 & 100.0 & 30 & 30.0 \\
15 & 13 & 61.5 & & 11 & 18.2 \\
16 & 3 & 100.0 & 31 & 19.4 \\
$17 *$ & 38 & 36.8 & 15 & 6.7 \\
18 & 10 & 60.0 & 34 & 0.0 \\
19 & 11 & 36.4 & 20 & 0.0 \\
\hline
\end{tabular}

* Indicate open estates.

provinces of Ciudad Real and Toledo (region of Castilla-La Mancha, $N=14$ ) and border areas (regions of Andalucía, $N=4$; and Extremadura, $N=1$ ). Geographical coordinates are from $37^{\circ} 13^{\prime} 48^{\prime \prime} \mathrm{N}$ to $39^{\circ} 31^{\prime} \quad 43^{\prime \prime} \mathrm{N}$ in latitude and $06^{\circ} 34^{\prime}, 06^{\prime \prime} \mathrm{W}$ to $2^{\circ} 25^{\prime}, 54^{\prime \prime} \mathrm{W}$ in longitude (Fig. 1). Sampled hunting estates ranged in size from 408 to 19328 hectares. We chose a sample of sites that exhibited a range of management factors, variations in deer and wild boar abundance and landscape diversity. Sampling took place during the regular hunting seasons (October-February), from October 1999 to February 2004. We obtained data from 574 red deer and 412 wild boar culled 


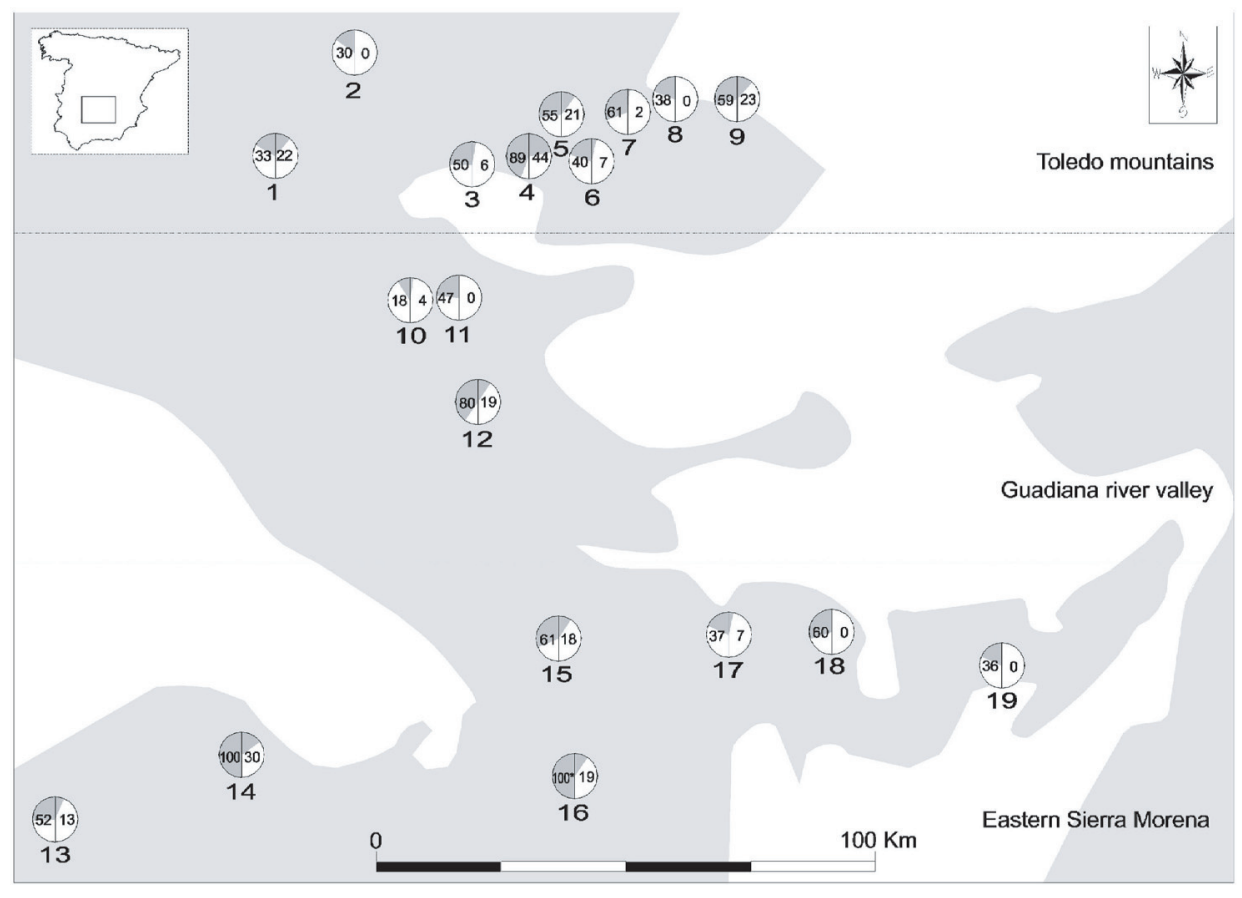

Figure 1. Map of south central Spain (woodlands are shaded) showing the sampling sites. Number inside the left semi-circle represents TBL prevalence in the wild boar, and left semi-circle dark portion represents TBL prevalence in the wild boar in relation to total semi-circle (100\%). Right semi-circle similarly applies to the red deer.

by hunters in the different estates. In the field, we arbitrarily sampled a random age and sex stratified subset of individuals of each species. A necropsy was performed, including detailed determination of morphometry, weight, and sex. Based on tooth eruption patterns, boars between 7 and 12 months were classified as either juveniles $(N=92)$, sub-adults of between 12 and 24 months $(N=154)$, or adults of over 2 years of age $(N=161)$ [29] (approximate age could not be determined for 7 individuals). In the case of the red deer, age was determined from sectioning incisor 1 [18] and animals were grouped into subadults (3 to 4 years) $N=167$ and (4) adults ( $\geq 5$ years) $N=396$ (approximate age and sex could not be determined for 11 individuals).
The presence of TBL was diagnosed by necropsy of the entire animal with macroscopic inspection of lymph nodes and abdominal and thoracic organs. Lymph nodes were dissected and sectioned serially and systematically examined for gross lesions (see $[10,11,34]$ for details). The presence of TB infection at the level of the estate was confirmed by culture and using data from a separate molecular study, which was based on a sub-sample of the same animals [11]. Some misclassification could have resulted from the omission of confirmatory cultures from all animals, but it was impossible to quantify how such bias may have influenced prevalence estimates for both species. Nevertheless, TBL criterion provided relative values that were comparable between localities, and permitted 
exploratory analyses of risk factors. The diagnostic value of TBL for epidemiological analyses in the study area is further discussed in [34].

\subsection{Management and environmental variables}

We visited the sampling sites in September 2002, immediately before the hunting season, in order to obtain field estimates of the relative abundance of wild boar and red deer and habitat variables. The habitat and management variables considered in the study were chosen on the basis of their likely epidemiological relevance and potential influence on the characteristics of wild ungulates and livestock (Tab. II). Habitat use and structure in the 19 study areas were recorded at points spaced every $200 \mathrm{~m}$ along linear transects $(N=20$ points per estate) and were used to calculate mean values for each estate. Interviews were carried out with gamekeepers to characterise the management practices employed on each estate. Data was collected on general estate-related features, watering sites (availability and number of artificial waterholes and natural water bodies on each estate), feeding practices, the number and location of livestock (and their exposure to wild ungulates) and the presence of other large game species (Tab. II). All variables were related to the year 2002.

\subsection{Estimation of red deer and wild boar relative abundance}

Wild boar relative abundance estimates were based on dropping frequency counts [31]. Briefly, each count consisted of $N=40$ transects of $100 \mathrm{~m}$, divided into 10 sectors of $10 \mathrm{~m}$ in length. Dropping frequency was defined as the average number of $10 \mathrm{~m}$ sectors with wild boar droppings present in each transect
$(\mathrm{DF}=\Sigma \mathrm{D} i / n$; where " $\mathrm{D}$ " is the number of dropping-positive sectors and ranges from 0 to 10 , and " $n$ " is the number of $100 \mathrm{~m}$ transects, usually 40). Red deer relative abundance data was obtained by spotlighting at night. Counts were transformed into indices of abundance per $\mathrm{km} \mathrm{[35]}$ and to deer per ha [17] (mean transect length $14.84 \pm 13.90 \mathrm{~km}$ ). At least one experienced observer (Joaquin Vicente and Christian Gortazar) participated in each transect.

\subsection{Statistical analysis}

Non-parametric Mann-Whitney tests were used to compare TBL prevalence between fenced and open estates for wild boar and red deer, respectively. Quantitative exploratory analysis of risk factors for TBL was carried out using a two-stage analysis. First, the associations between the hypothesised risk factors and wild boar and red deer TBL prevalences (\%) respectively, were analysed using Spearman Rank correlations $(N=19)$. All the factors that captured the effect of any set of highly correlated variables for which $P<0.1$ were selected for inclusion in the final models for each species (Tab. II). For categorical variables, nonparametric Kruskall-Wallis analysis was used for initial assessment of associations, and selected variables were then jointly evaluated in a multiple logistic model. The individual TBL status of wild boar $(N=407)$ and red deer $(N=565)$ were the respective response variables (as binomial variables, i.e. present or absent) in two separate models. Since sampling across different populations was not homogeneous in relation to age and sex, and because previous work suggested these factors were influential [34], statistical analyses were conducted at the individual level to control for them. Age was included as a continuous discrete explanatory variable in models 
Table II. Variables included in the study, indicating which were significantly associated with TBL (excluding other highly correlated variables) in wild boar ${ }^{\mathrm{a}}$ and $\operatorname{red~}^{\mathrm{deer}}{ }^{\mathrm{b}}$ models $\left(r_{S}, P<0.1\right.$, $N=19$ ).

\section{Estate-related features and management practices}

General: Geographic location, area (ha), boundaries limiting with big hunting estates (\%), introductions or purchasing (binomial), captures (binomial), predator control (binomial), agricultural lands for hunting (ha and \% related to the estate), fencing status (binomial), years since fencing ${ }^{\mathrm{a}}$, boundary fenced (\%)

Supplemental feeding: Supplemental feeding for wild boar (binomial), Supplemental feeding for red deer (binomial), feeding method (binomial: spreading or provided in feeders), wild boar and red deer sharing feeding sites (binomial), wild boar feeding site density, red deer feeding site density, number of wild boar per feeding site inde $\mathrm{x}^{\mathrm{b}}$ (wild boar dropping frequency abundance index/wild boar feeding site density), number of red deer per feeding site $^{\mathrm{b}}$ (deer per $100 \mathrm{ha} /$ red deer feeding sites density), baiting previous to hunting season (binomial)

Watering: Number of wild boar watering sites, number of red deer watering sites, wild boar watering site density, red deer watering site density, number of wild boar per watering site index ${ }^{\mathrm{a}, \mathrm{b}}$ (wild boar dropping frequency abundance index/ wild boar watering site density), number of red deer per watering site (deer per $100 \mathrm{ha} /$ red deer watering sites density)

Host demography: Wild boar dropping frequency abundance inde ${ }^{\mathrm{a}, \mathrm{b}}$, red deer kilometric abundance index (deer $/ \mathrm{km})$, deer density (deer/ha).

Other wildlife: Kilometric abundance indices: Mouflon, fallow deer, roe deer, Iberian hare, wild rabbit, fox, other carnivores.

Dropping or pellet abundance frequency indices: Iberian hare, wild rabbit, carnivore

Livestock: Livestock (cattle, goat and sheep, binomial), sheep density (per ha), historic livestock presence (years), livestock sharing pastures, feeders or watering site with hunting (binomial)

\section{Estate-related general environmental conditions (mean values for each estate)}

Habitat availability (\%): Scrublands, Dehesa (savannah-like habitat), Mediterranean hardwood forest $^{\mathrm{a}, \mathrm{b}}$ (Quercus spp.), pine plantations, pastures, riparian habitat, agricultural areas

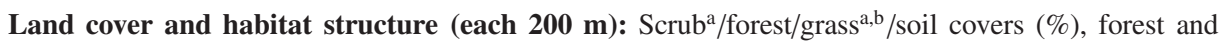
scrub diversity/10 m, No. Quercus trees/10 m, soil compactness (cat.: 1-5)

for both wild boar and red deer and sex was included as a categorical binomial explanatory variable in the red deer model. To standardise comparisons, we included in the analysis only wild boar over 7 months old and only red deer over 2 years old [34]. The number of non-fenced facilities ( 2 out of 19 sampling sites, see Tab. II) was too small to support a separate statistical analysis, and thus they were excluded from the analysis. We used a stepwise strategy to obtain the final model.

Mantel tests [19] were used to assess the spatial association between TBL prevalence in wild boar and red deer across different estates, respectively. One matrix was a measure of dissimilarity between every pair of estates in terms of their TBL prevalence (the difference), whilst the second was the Euclidean distance between estates. The Pearson correlation coefficient between the elements of the matrices was used as the test statistic and its significance was assessed by permuting the row labels of one matrix relative to the other five thousand times [19]. The distance between estates was assumed to be the distance between their nearest sampling points used to characterise environmental and management features, and was calculated with the "Distance Operator" tool of Idrisi 32 software version I32.21 (The Clark labs. ${ }^{\circledR}$, 
Table III. General statistics for the most relevant land uses, habitat data and management practices at the estate level $(N=19)$.

\begin{tabular}{lccc}
\hline Variable & Mean \pm SD & Median $(25$ and 75\% quartiles) & Range \\
\hline Estate area (ha) & $4616 \pm 4637$ & $3000(1700-6862)$ & $408-19328$ \\
Estate boundary fenced (\%) & $87.1 \pm 32.0$ & $100(100-100)$ & $0-100$ \\
Time completely fenced (years since) & $21 \pm 12.6$ & $19(14-34)$ & $0-43$ \\
Cultivated dehesas or pastures for hunting $(\%)$ & $8.5 \pm 15.5$ & $2.1(0.1-13.3)$ & $0-45.5$ \\
Wild boar feeding sites (No. per 100 ha) & $0.3 \pm 0.01$ & $0(0-0.53)$ & $0-1.8$ \\
Red deer feeding sites (No. per 100 ha) & $0.3 \pm 0.01$ & $0(0-0.65)$ & $0-1.8$ \\
Wild boar per feeding site index & $89.2 \pm 208.1$ & $0(0-95.1)$ & $0-880$ \\
Number of red deer per feeding site & $32.1 \pm 65.0$ & $0(0-49.0)$ & $0-261.9$ \\
Number of watering sites (No. per 100 ha) & $0.6 \pm 0.5$ & $0.3(0.1-0.6)$ & $0.11-2.3$ \\
Number of wild boar per watering site index & $79.7 \pm 61.6$ & $77.9(16.9-129.5)$ & $0-188.9$ \\
Number of red deer per watering site & $59.5 \pm 39.0$ & $57.5(29.7-92.9)$ & $0-130.0$ \\
Red deer abundance index (KAI) & $9.9 \pm 5.1$ & $6.4(5.6-13.7)$ & $3.33-18.4$ \\
Red deer abundance (deer per 100 ha) & $24.4 \pm 16.3$ & $17.4(11.0-40.9)$ & $3.42-55.1$ \\
Wild boar abundance (dropping frequency & $0.6 \pm 0.9$ & $0.2(0.1-0.7)$ & $0-4$ \\
index) & & & \\
Land uses (\%) & & & \\
$\quad$ Quercus spp. forest & $30.7 \pm 24.8$ & $23.8(4.8-35.3)$ & $4.5-100$ \\
$\quad$ Dehesa & $28.5 \pm 26.4$ & $28.6(0-55)$ & $0-80.9$ \\
$\quad$ Pine plantation & $17.4 \pm 27.2$ & $0(0-37.5)$ & $0-71.4$ \\
Pastures & $0.6 \pm 1.9$ & $0.1(0-0.3)$ & $0-7.2$ \\
$\quad$ Scrubland & $20.6 \pm 20.2$ & $11.5(4.8-35.0)$ & $0-61.9$ \\
Habitat structure (\% in 25 m radio) & & & \\
$\quad$ Scrub cover & $32.7 \pm 11.9$ & $31.5(22.7-41.7)$ & $16.2-58.7$ \\
Quercus spp. forest cover & $22.1 \pm 11.3$ & $23.8(4.8-35.2)$ & $0.3-50.2$ \\
Grass cover & $30.9 \pm 13.9$ & $23.9(4.8-35.2)$ & $7.6-50.6$ \\
Soil cover & $29.02 \pm 10.49$ & $28.6(21.3-38.9)$ & $10-51.67$ \\
\hline
\end{tabular}

Clark University, Massachusetts, USA). Statistical significance was assumed wherever $P<0.05$. We employed SPSS 10.0.6 (SPSS Inc., 1999) and Genstat (Genstat 5 Committee 1993) statistical packages.

\section{RESULTS}

\subsection{Characteristics of the sampling estates and populations}

Habitat use and structure, and management practices in the study estates are described in Table III. The most common habitats in the study area were Quercus spp. forests (Evergreen oak Quercus ilex as predominant species), open pasture with Quercus spp. trees (savannah-like habitats typically known as "Dehesas") and Mediterranean scrublands (Cistus spp. and Quercus spp. as predominant species).

Fifteen of the 19 study estates were completely fenced and two were incompletely fenced $(60 \%$ and over $95 \%$ of the perimeter respectively, the latter considered as fenced for statistical analyses) when the interviews were performed. Seven out of the 19 study sites fed wild boar artificially all year round and only 12 provided food to wild boar in the form of bait immediately before and during the hunting season. Amongst the 19 sites, red deer were fed regularly all year round at 
eight, while 12 (including those feeding all year round) provided food as bait both immediately before and during the hunting season. Seven out of the 19 study estates fed both wild boar and red deer all year round. Domestic sheep were kept on only three of the study estates and neither cattle nor goats were present on any. Thirteen of the interviewed game managers reported finding emaciated and moribund wild boar and/or red deer, mainly in the summer and usually near watering sites, although these were not specifically associated with TB infections.

\subsection{Risk assessment}

The distribution of TBL across wild boar and red deer populations from the study sites is shown in Table I and Figure 1. No statistical significant spatial association was found between the dissimilarity values for the TBL prevalence per estate and the Euclidean distance between them for either species (wild boar Pearson $r=-0.10$, $N=171 ; P=0.80$, red deer Pearson $r=-0.13, N=171, P=0.87)$.

Those potential risk factors that were selected for inclusion in subsequent models are shown in Table II (the correlation coefficients ranged from 0.39 to 0.64 in absolute value). For both the wild boar and red deer these models included an aggregation index for wild boar at watering sites (Fig. 2), the wild boar dropping frequency index (an abundance estimate) and the availability of Quercus spp. forest habitat and grass cover. Aggregations of boar and red deer at feeding sites were included only in the red deer model. Scrub cover was selected only in the final wild boar model (the only negative correlation, $R_{S}=$ $-0.59, P<0.01, N=19$ ).

TB prevalence in both the wild boar and red deer did not differ when comparing open $(N=3)$ and fenced estates $(N=16)$ (Mann-Whitney test, $P$ always
$>0.05)$. The range of management practices, host abundances and habitat descriptors for open estates overlapped with those of fenced estates. Nevertheless, open estates were excluded from the models since they were numerically under-represented.

The definitive logistic models fitted adequately (Hosmer and Lemeshow goodnessof-fit test: $\chi^{2}=4.48$, d.f. $8, P=0.81$, $\chi^{2}=11.33$, d.f. $=8, P=0.18$ for wild boar and red deer, respectively). However, neither model explained the majority of the variation in the data $\left(R_{\text {Nagelkerke }}^{2}=0.15\right.$, $R_{\text {Nagelkerke }}^{2}=0.13$ for the wild boar and red deer respectively). In both cases, the null hypothesis $\left(\mathrm{H}_{0}\right)$ of $\beta=0$ was rejected (Wald $\chi^{2}, P<0.05$ in both models). The results of the wild boar and red deer models are shown in Table IV. For significant terms in the models, confidence intervals for the Wald statistic did not span the null Odds ratio (exponentiated $\beta$ ) value in any case (Tab. IV). The aggregation of the wild boar at artificial watering sites was significantly associated with an increased risk of TBL presence in both species (Figs. 2a and 2b). Aggregation of the wild boar at feeding sites significantly increased the risk of TBL presence in red deer (the index value was over twice as high in TBL positive animals compared to negative animals). Scrubland cover was significantly associated with a decreased individual risk of TBL presence in the wild boar, and there was a marginal positive association $(P=0.06$, Tab. IV) between the availability of Quercus spp. forest habitat and the risk of testing positive for TBL.

\section{DISCUSSION}

The results of this study confirm previous findings by the authors [34], in suggesting that differences exist between estates in terms of not only the presence, but in particular in the prevalence of TBL. To date it has been unusual to 
(a)

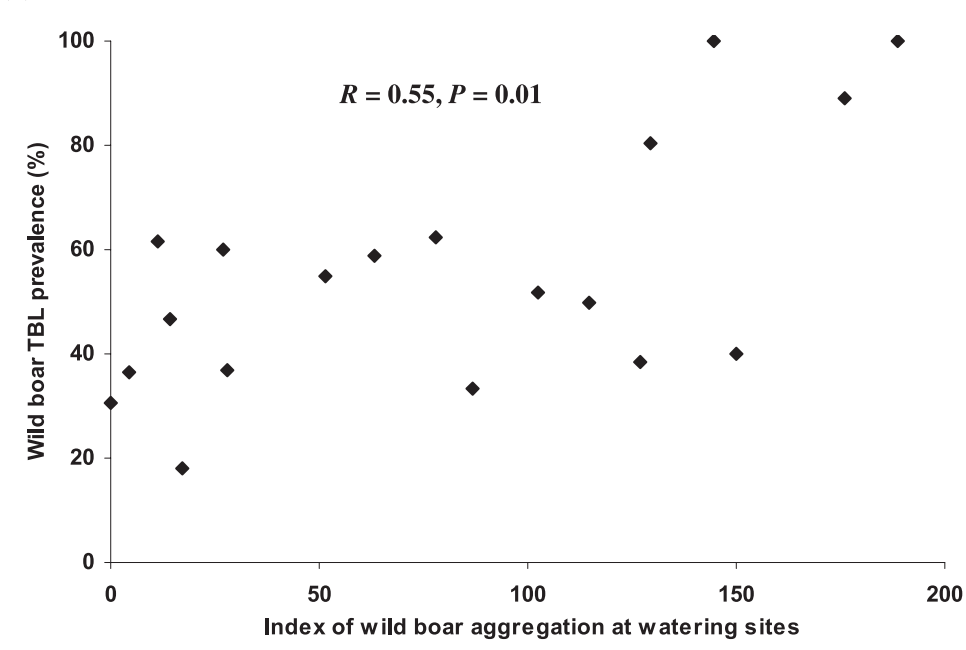

(b)

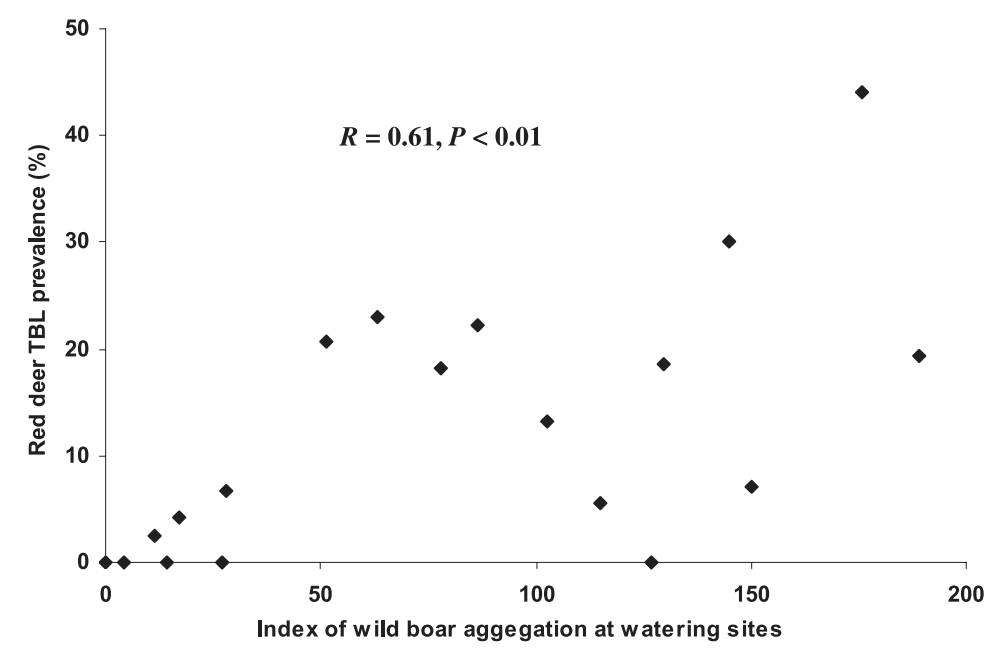

Figure 2. Mean TBL prevalence (\%) in relation to the estimated potential aggregation of wild boar (a) and red deer (b) at watering sites at estate level $(N=19)$.

find a TBL-free ungulate game population in SCS. The main finding of the present study is the association between the aggregation of hosts (mainly a consequence of hunting management in Mediterranean habitats) and the presence of TBL in potential TB reservoirs. Previous re- ports suggested similar relationships for other infectious pathogens in the study area [31]. Our spatial analyses of the TBL pattern across estates revealed that management units close together in space did not tend to be similar in terms of TBL prevalence, which suggests that there was 
Table IV. Final logistic regression models for the association between hunting estate characteristics and the individual TBL status of wild boar and red deer respectively.

\begin{tabular}{lccccc}
\hline Variable & $\beta$ (S.E.) & Wald $_{95 \% \mathrm{CI}}$ & d.f. & $P$ Sig. & $\operatorname{Exp}(\beta)_{95 \% \mathrm{CI}}$ \\
\hline Red deer model & & & & & \\
Sex & $0.55(0.27)$ & $3.96(2.02-5.90)$ & 1 & 0.04 & $1.73(1.01-2.96)$ \\
Wild boar/watering site & $0.01(0.002)$ & $15.99(12.79-19.19)$ & 1 & $<0.001$ & $1.01(1.01-1.02)$ \\
Wild boar/feeding site & $0.001(0.0005)$ & $3.87(1.94-5.80)$ & 1 & 0.05 & $1.00(1.00-1.01)$ \\
Wild boar model & & & & & \\
Age class & $0.54(0.15)$ & $13.23(9.55-16.91)$ & 1 & $<0.001$ & $1.71(1.28-2.28)$ \\
Wild boar/watering site & $0.01(0.002)$ & $10.08(8.66-12.09)$ & 1 & 0.001 & $1.01(1.00-1.01)$ \\
Quercus spp. forest & $1.23(0.65)$ & $3.52(1.66-5.38)$ & 1 & 0.06 & $3.43(0.95-12.47)$ \\
Scrubland cover & $-0.02(0.01)$ & $6.35(3.175-9.52)$ & 1 & 0.01 & $0.98(0.96-0.99)$ \\
\hline
\end{tabular}

no spatial aggregation (which would lead to spatial autocorrelation in our data). In other words, after accounting for individual factors (which are species-specific) management scale factors seemed to be more influential in explaining differences in TBL prevalence between estates than their spatial location. This suggests that the management characteristics of each estate are the major determinants of disease transmission, and should therefore be considered as the appropriate target for control policies. For example, in the present paper estates that were geographically close sometimes had very different levels of TBL (e.g. study sites in the Toledo Mountains exhibited TBL prevalence from $18 \%$ to $90 \%$ in wild boars, Fig. 1). The sampling design we employed included a broad variety of hunting management practices and Mediterranean landscapes from throughout SCS (Tab. III). For instance, the number of red deer per feeding site, the index of wild boar per feeding site and the proportion of open grassland (cultivated dehesas, pastures for big game) varied widely amongst estates, although unfenced populations were under-represented. Red deer and wild boar on fenced estates can be considered as semi-domestic livestock and are now present in SCS at far higher densities than several decades ago $[9,30]$, where TB has become established as a selfmaintained, endemic disease [14, 34]. The potential influence of game management intensification on TB dynamics may be illustrated by the positive association at the estate level between the time at which an estate was fenced and the prevalence of TBL in wild boar populations.

The present analyses of risk factors constitute a correlational study, so cause and effect cannot be demonstrated, and we therefore consider our conclusions as exploratory. These analyses included variables related to both management practices and habitat structure; nevertheless, it is difficult to isolate the effect of a particular component. For example, the aggregation of animals at waterholes created on natural riverbeds is a factor related to both management and natural features of Mediterranean habitats. Management of ungulates in these habitats tends to promote aggregation of ungulates, and subsequently enhances opportunities for transmission. This may arise because ungulates come into contact with a higher proportion of individuals either at the inter- and intraspecific levels, or with a more heavily contaminated habitat (i.e. direct and/or indirect mycobacteria transmission). In particular, we found that the potential aggregation of wild boar at watering sites 
significantly increased the risk that an individual was TBL positive, in both host species. These findings were in agreement with the known health risks to small game in southern Spain associated with artificial feeding and water provision $[15,20]$. The frequency of contact between wild mammals at watering sites could increase during the drought season (summer), since the few water holes are more intensely used. TB spread may occur by ingestion or inhalation of nasal and oral excretions from coughing or sneezing of infected individuals or from infected dust particles [5]. Spread may also occur indirectly from contaminated vegetation, water, mud or fomites [24]. It is known that oral excretion from affected mandibular lymphnodes occurs through fistulae [10]. Wild boar activity around these places (such as wallowing, brushing, drinking, defecating, urinating, and mating) may enhance the possibilities of environmental contamination and TB transmission. Watering sites may also concentrate mating behaviour and brushing at the end of the summer in red deer [4]. In addition, the practice of providing artificial water at these sites may cause the formation of a multiple "piosphere" effect, which consists in the existence of a zone of high ungulate utilisation in woody vegetation extending far beyond the area [2], and subsequently, an increased risk of indirect transmission. Models for each species suggest that interspecific indirect transmission at these sites is probably more likely to occur from the wild boar to red deer. Both the wild boar and red deer have shared free access to watering sites, although more research is needed concerning the use and inter and intraspecific interactions at these points. For some potential hosts the main route of TB infection may be ingestion of infected carrion [28], and in the study sites described here TB-infected carcasses and subsequent scavenging by wild boars both occur (the authors, unpublished observations). In addition, se- vere droughts in Mediterranean habitats and seasonal scarcity of water resources may exacerbate the effect of TB infection on hosts [3] and, watering (and also feeding) sites may attract tuberculous animals in the advanced stages of infection (the authors, unpublished observations). Watering sites used by domestic livestock could also be frequented by wild ungulates.

The presence of TBL in red deer was positively associated with the abundance of wild boar per feeding site index. This may be explained in part by indirect interspecific transmission opportunities, which seem most probable in the direction of wild boar to red deer than vice versa. Deer have free access to wild boar supplementary food since this is provided by spreading on the ground. The prevalence of TBL in the wild boar is higher than in red deer, and they may contaminate the environment with mycobacteria in places where the two species co-exist [10]. In contrast, red deer are fed with cereals or concentrate pellets, frequently given in elevated feeders, which are not accessible to wild boar. M. bovis can survive for extended periods of time on different types of animal feeds (unpublished data cited by $\left.[27]^{1}\right)$. The importance of transmission by direct contact (aerosol transmission) or by indirect contact via contamination of feed sites has been demonstrated in white-tailed deer (Odocoilus virginianus) in Michigan [10,25]. However, we failed to detect any significant relationships consistent with intraspecific transmission of TB amongst deer at feeding sites. Higher prevalences of TBL in red deer in the present study area compared to previously published estimates have been suggested to be due in part to interspecific transmission from wild boar [34], but confirmation requires more observational and experimental research.

\footnotetext{
${ }^{1}$ Palmer M.V., personnal communication.
} 
A decreased TBL prevalence in wild boar (and in red deer in the initial stage of analysis) was seen in estates with higher percentages of scrub cover. Scrublands provide food for deer to browse but since they are less attractive to wild boar, interactions and opportunities for transmission between the two species are less likely. Conversely, the presence of TBL in individual wild boar and in red deer at the population level, were marginally $(P=0.06)$ and positively associated with the availability of Quercus spp. forest (Mediterranean hardwood). Miller et al. [21] suggested that woodland areas provide shady, moist conditions under which $M$. bovis might survive longer in the environment. Quercus spp. woodlands could provide the best available environment for mycobacteria persistence in Mediterranean habitats, where rainfall is highly variable amongst seasons, but retention of moisture in woodlands may favour the environmental persistence of mycobacteria [32, 33]. Such habitats become more important in an epidemiological sense if they are positively selected by hosts. Quercus spp. acorns from Mediterranean woodlands are intensively foraged by wild ungulates during the autumn. If environmental contamination exists, wild boar and red deer feeding in the area (by rooting and muzzling while searching for acorns) could either ingest or inhale mycobacteria. Acorn grazing is also a common practice in free-roaming Iberian pigs in large areas of southern Spain [26] and hence infectious interactions could occur.

In both species, levels of TBL in unfenced estates overlapped with the range found for fenced populations (Tab. II), suggesting that factors other than fencing and provisioning may be also important determinants of TBL prevalence. This finding also raises the possibility that captive wildlife may act as disease reservoirs and risks for native free-ranging wildlife in addition to domestic livestock. Since unfenced populations were numerically under-represented in the present study, further research is required for a robust comparison of fenced and unfenced estates.

The current study represents an initial identification of the potential epidemiological risk factors that may be important in the development of strategies aimed at controlling TB in Spain. Wild game ungulates are not currently considered in disease control programmes, but recent studies, including the present work, suggest that to do so could have significant consequences for disease control efforts. Host populations enclosed by a fence (more or less permeable) are similar in many ways to extensively managed livestock, and therefore could be referred to as captive or semidomesticated animals. However, a precise definition for large game mammals in fenced estates is problematic since management systems vary widely $[12,16]$. This is even more complex for the ubiquitous wild boar, which is easily able to "undercross" fences.

Although bovine TB in wildlife is likely to have originated from domestic cattle [24], wildlife reservoirs may act as sources of infection for livestock in some areas, and therefore could hamper disease control programmes. A possible link between the presence of livestock in the past and subsequent detection of Mycobacterium tuberculosis complex strains in boar and deer current big game was established in our study area by [11]. Because TB is extremely difficult to eradicate from wildlife once established, the priority is to clearly identify the route of transmission to cattle, and then control it. Although activities are now clearly segregated across the majority of estates, extensive livestock production (cattle, goats and swine) in marginal areas of SCS Spain still overlaps with those devoted to hunting. Our results suggest that indirect transmission of TB in grazing areas across the livestockgame interface is likely to occur. Game 
ungulates that can easily cross fences may play an important role in transmission at the wildlife/livestock interface. Foraging excursions of livestock into woodlands devoted to hunting (a practice still common in some marginal lands in SCS) may also be a route of transmission between big game and domestic livestock. As mentioned above, watering sites for domestic livestock may also attract wild ungulates, especially during the dry season, with subsequent enhanced opportunities for infectious interactions. Investigations into the patterns of dissemination of bacilli in the environment and the mode of transmission of infection between wild ungulates and livestock are research priorities. The development of effective and sustainable TB management policies will need to take account of the relationships between estate husbandry practices and the transmission of infection at the large game-domestic livestock interface.

\section{ACKNOWLEDGEMENTS}

This study was supported by project AGL2001-3947, MCYT and FEDER and project AGL2005-07401 MEC. This is also a contribution to the agreement between FGUCLM and Grupo Santander, and to the agreement between Yolanda Fierro and the UCLM. We wish to thank A. Peña, and all our colleagues at IREC for their kind help. We are grateful to Neil Walker for statistical advice and D. Richard Delahay for its comments on the manuscript and edition of the English.

\section{REFERENCES}

[1] Artois M., Delahay R., Guberti V., Cheeseman C., Control of infectious diseases of wildlife in Europe, Vet. J. (2001) 162:141-152.

[2] Brits J., Van Rooyen M.W., Van Rooyen N., Ecological impact of large herbivores on the woody vegetation at selected watering points on the eastern basaltic soils in the Kruger National Park, Afr. J. Ecol. (2002) 40:53-60.
[3] Caron A., Cross P.C., Du Toit J.T., Ecological implications of bovine tuberculosis in African buffalo herds, Ecol. Appl. (2003) 13:1338-1345.

[4] Carranza J., Fernandez-Llario P., Gomendio M., Correlates of territoriality in rutting red deer, Ethology (1996) 102:793-805.

[5] Cousins D.V., Mycobacterium bovis infection and control in domestic livestock, Rev. Sci. Tech. Off. Int. Epizoot. (2001) 20:71-85.

[6] De Lisle G.W., Joyce M.A., Yates G.F., Wards B.J., Hoyle F.P., Mycobacteriun avium infection in a farmed deer herd, N. Z. Vet. J. (1995) 43:1-3.

[7] Delahay R.J., De Leeuw A.S., Barlow A.M., Clifton-Hadley R.S., Cheeseman, C.L., The status of Mycobacterium bovis infection in UK wild mammals: a review, Vet. J. (2003) 164:90-105.

[8] Gilbert M., Mitchell A., Bourn D., Mawdsley J., Clifton-Hadley R., Win W., Cattle movements and bovine tuberculosis in Great Britain, Nature (2005) 435:491-496.

[9] Gortazar C., Herrero J., Villafuerte R., Marco J., Historical examination of the status of large mammals in Aragon, Spain, Mammalia (2000) 64:411-422.

[10] Gortazar C., Vicente J., Gavier-Widen D., Pathology of bovine tuberculosis in the European wild boar (Sus Scrofa), Vet. Rec. (2003) 152:779-780.

[11] Gortazar C., Vicente J., Samper S., Garrido J., Fernández-De-Mera I.G., Gavín P., Juste R.A., Martín C., Acevedo P., De La Puente M., Höfle U., Molecular characterization of Mycobacterium tuberculosis complex isolates from wild ungulates in South-Central Spain, Vet. Res. (2005) 36:43-52.

[12] Gortazar C., Acevedo P., Ruiz-Fons F., Vicente J., Disease risks and overabundance of game species, Eur. J. Wild. Res. (2006) 52:81-87.

[13] Haydon D.T., Cleaveland S., Taylor L.H., Laurenson M.K., Identifying reservoirs of infection: a conceptual and practical challenge, Emerg. Infect. Dis. (2002) 8:1468-1473.

[14] Hermoso de Mendoza J., Parra A., Tato A., Alonso J.M., Rey J.M., Peña A., GarciaSanchez A., Larrasa J., Teixido J., Manzano G., Cerrato R., Pereira G., Fernandez-Llario P., Hermoso de Mendoza M., Bovine tuberculosis in wild boar (Sus scrofa), red deer (Cervus elaphus) and cattle (Bos taurus) 
in a Mediterranean ecosystem (1992-2004), Prev. Vet. Med. (2006) 74:239-247.

[15] Höfle U., Gortazar C., Ortíz J.A., Knispel B., Kaleta E.F., Outbreak of Trichomonosis in a woodpigeon wintering roost, Eur. J. Wildl. Res. (2004) 50:73-77.

[16] Hunter D.L., Tuberculosis in free-ranging, semi-free-ranging and captive cervids, Rev. Sci. Tech. Off. Int. Epizoot. (1996) 15:171-181.

[17] Jarvinen O., Vaisanen R.A., Estimating relative densities of breeding birds in the line transcect method, Oikos (1975) 26:316-322.

[18] Klevezal G.A., Kleinenberg S.E., Age determination of mammals from annual layers in teeth and bones, Academy of Sciences USSR Translation Dept. of the Interior and National Science Foundation, U.S. Dept. of Commerce, Clearinghouse for Federal Scientific and Technical Information, Springfield, 1967.

[19] Manly B.F.G., Randomization, Bootstrap and Monte Carlo methods in Biology, Chapman and Hall, London, 1997.

[20] Millan J., Gortazar C., Villafuerte R., Mycobacterium avium disease in wild redlegged partridges (Alectoris rufa), Eur. J. Wildl. Res. (2004) 50:97-99.

[21] Miller R., Kaneene J.B., Fitzgerald S.D., Schmitt S.M., Evaluation of the influence of supplemental feeding of white-tailed deer (Odocoileus virginianus) on the prevalence of bovine tuberculosis in the Michigan wild deer population, J. Wildl. Dis. (2003) 39:84-95.

[22] Ministry of Agriculture, Programa nacional de erradicacion de tuberculosis bovina presentado por España para el 2006, Secretaria General de Agricultura, Madrid, 2005.

[23] Mollenkopf H.J., Kursar M., Kaufmann S.H., Immune response to postprimary tuberculosis in mice: Mycobacterium tuberculosis and Mycobacterium bovis bacille CalmetteGuerin induce equal protection, J. Infect. Dis. (2004) 190:588-597.

[24] Morris R.S., Pfeifer D.U., Jakson R., The epidemiology of Mycobacterium bovis infections, Vet. Microbiol. (1994) 40:153-177.

[25] O’brien D.J., Schmitt S.M., Fierke J.S., Hogle S.A., Winterstein S.R., Cooley T.M., Moritz W.E., Diegel K.L., Fitzgerald S.D., Berry D.E., Kaneene J.B., Epidemiology of Mycobacterium bovis in free-ranging whitetailed deer, Michigan, USA, 1995-2000, Prev. Vet. Med. (2000) 54:47-63.
[26] Parra A., Fernandez-Llario P., Tato A., Larrasa J., García A., Alonso J.M., De Mendoza M.H., De Mendoza J.H., Epidemiology of Mycobacterium bovis infections of pigs and wild boars using a molecular approach, Vet. Microbiol. (2003) 97:123-133.

[27] Palmer M.V., Waters W.R., Whipple D.L., Shared feed as a means of deer-to-deer transmission of Mycobacterium bovis, J. Wildl. Dis. (2004) 40:87-91.

[28] Ragg J.R., Mackintosh C.G., Moller H., The scavenging behaviour of ferrets (Mustela furo), feral cats (Felis domesticus), possums (Trichosurus vulpecula), hedgehogs (Erinaceus europaeus) and harrier hawks (Circus approximans) on pastoral farmland in New Zealand: Implications for bovine tuberculosis transmission, N. Z. Vet. J. (2000) 48:166-175.

[29] Sáenz De Buruaga M., Lucio A.J., Purroy J., Reconocimiento de sexo y edad en especies cinegéticas, Diputación Foral de Alava, Vitoria, 1991.

[30] Sáez-Royuela C., Tellería J.L., The increased population of the wild boar (Sus scrofa L.) in Europe, Mammal Rev. (1986) 16:97-101.

[31] Vicente J., Segalés J., Höfle U., Balasch M., Plana-Durán J., Domingo M., Gortazar C., Epidemiological study on porcine circovirus type 2 (PCV2) infection in the European wild boar (Sus scrofa), Vet. Res. (2004) 35:243-253.

[32] Vicente J., Fierro Y., Gortazar C., Seasonal dynamics of the fecal excretion of Elaphostrongylus cervi (Nematoda, Metastrongyloidea) first stage larvae in Iberian red deer (Cervus elaphus hispanicus) from South Spain, Parasitol. Res. (2005) 95:60-64.

[33] Vicente J., Fernández de Mera I.G., Gortazar C., Epidemiology and risk factors analysis of elaphostrongylosis in red deer (Cervus elaphus) from Spain, Parasitol. Res. (2006) 98:77-85.

[34] Vicente J., Höfle U., Garrido J.M., Fernández de Mera I.G., Juste R., Barral M., Gortazar C., Wild boar and red deer display high prevalences of tuberculosis-like lesions in Spain, Vet. Res. (2006) 37:107-119.

[35] Whipple J.D., Rollins D., Schacht W.H., A field simulation for assessing accuracy of spotlight deer surveys, Wildl. Soc. Bull. (1994) 22:667-673.

[36] Wobeser G., New and emerging diseases, The wildlife interface, Can. Vet. J. (2002) 43:793. 